\title{
GÊNERO E COMBATE À POBREZA: PROGRAMA BOLSA FAMÍLIA
}

\author{
SILVANA APARECIDA MARIANO \\ Universidade Federal de Uberlândia \\ CÁSSIA MARIA CARLOTO \\ Universidade Estadual de Londrina
}

\begin{abstract}
Resumo: A política de assistência social brasileira orienta-se pela perspectiva de ações de combate à pobreza, com prioridade aos programas de transferência condicionada de renda. Esses são programas que priorizam o repasse de renda às mulheres e envolvem-nas em uma rede de obrigações e condicionalidades, a exemplo do Programa Bolsa Família. A prática encerrada no Programa Bolsa Família coloca em evidência algumas contradições entre as ações estatais e as demandas feministas, notadamente no que diz respeito à problematização acerca da maternidade. Esse é, então, um ponto central para o diálogo entre o feminismo e as políticas sociais estatais de combate.
\end{abstract}

Palavras-chave: Programa Bolsa Família; combate à pobreza; maternidade; gênero; feminismo.

\section{Introdução}

Os programas brasileiros de transferência condicionada de renda veem as mulheres como foco prioritário, e até objeto, de suas intervenções com vistas ao combate à pobreza. A mulher, a partir de seus papéis na esfera doméstica ou de reprodução, tem sido, portanto, a interlocutora principal dessas ações, tanto como titular do benefício quanto no cumprimento das condicionalidades impostas. O Programa Bolsa Família (PBF) é um exemplo paradigmático dessa política. Diante desse contexto, estudiosas feministas têm insistido que a categoria "gênero" não pode ser prescindida das análises sociológicas acerca das ações estatais, que têm por foco a família. Essa categoria de análise contribui para a compreensão da instrumentalização dos papéis femininos nessas políticas.

A implantação do PBF, de acordo com suas regras de seletividade e exigências de condicionalidades, bem como com as dimensões assumidas ao incluir mais de 11 milhões de famílias, expressa, em certa medida, a extensão da pobreza no Brasil. Do mesmo modo, a composição do público beneficiário ilustra o quadro de desigualdades persistente na

Copyright (c) 2009 by Revista Estudos Feministas. 
história da sociedade brasileira. De acordo com dados do Retrato das desigualdades de gênero e raça, podemos, mais uma vez, constatar que a pobreza brasileira tem sexo e cor.'

A presença mais notável de mulheres negras entre as pessoas pobres é reflexo de um processo histórico de (re)produção de desigualdades sociais. Essas desigualdades têm como eixos estruturantes os marcadores sociais como gênero e raça-etnia, os quais orientam a construção da cidadania e a efetivação de direitos no Ocidente. Portanto, sexo e cor são também definidores das desigualdades sociais.

Esse processo interfere diretamente na relação entre as mulheres, brancas e negras, e o Estado. Um ponto de ilustração a esse respeito é o modo como os grupos de mulheres estão sujeitos a obrigações impostas pelo Estado e geram efeitos para o tempo e o trabalho femininos. ${ }^{2}$ Tais obrigações se expressam no cumprimento de atividades e responsabilidades estipuladas pelas políticas sociais, com destaque para as políticas de desenvolvimento e, mais recentemente, para as de combate à pobreza. O Estado cobra das mulheres pobres a execução de tarefas relacionadas ao cuidado de crianças, adolescentes, idosos, doentes e pessoas com deficiência. Igualmente, convoca as mulheres para a participação em atividades extras, como, por exemplo, grupos de geração de trabalho e renda (com duvidosa potencialidade para a melhoria do bem-estar) e grupos de ações educativas, sendo estas, via de regra, relacionadas às tarefas reprodutivas. Ao fazê-lo, o Estado está gerando, para as mulheres pobres, responsabilidades ou sobrecarga de obrigações relacionadas à reprodução social. Consideramos esse tipo de ocupação do trabalho e do tempo das mulheres um dos fatores vinculados à desigualdade, entre homens e mulheres e entre estratos sociais, pois disponibiliza menos as mulheres para o trabalho remunerado. Esse fator deve ser colocado em evidência quando nos dedicamos a investigar o modo de inclusão das mulheres nas ações estatais, a exemplo do PBF, uma vez que esse programa opera instituindo condicionalidades nas áreas de educação, saúde e atividades complementares, como os grupos socioeducativos.

A principal questão que norteia nossa reflexão neste trabalho, em particular, é compreender o modo como o PBF, em uma estratégia de combate à pobreza, desenvolve mecanismos que reforçam a tradicional associação da mulher com a maternidade e as tarefas pertencentes à clássica esfera reprodutiva.

O PBF, dada sua extensão em número de famílias beneficiárias no país e sua capacidade de exercer influências nas relações entre os indivíduos envolvidos nas ações estatais, torna-se um importante objeto de análise de pesquisas preocupadas em refletir o modo como o Estado incorpora padrões de relações de gênero e concepções de família e de mulher em seus programas que se dirigem ao âmbito das relações de cuidado.

A reflexão aqui desenvolvida se inspira em pesquisa qualitativa realizada em Londrina, PR, a fim de trazer questões sobre as relações entre gênero e políticas de combate à pobreza de forma geral. Londrina é um município com avançado processo de implantação do novo sistema de gestão da Política Nacional de Assistência Social, o que inclui ações de acompanhamento às famílias beneficiárias do Programa Bolsa Família.

\section{Mulher e papéis de gênero no Programa Bolsa Família}

A política de assistência social brasileira orienta-se pela perspectiva das políticas de combate à pobreza. Desde a década de 1990 têm recebido destaque os programas focalizados de transferência de renda. Os principais deles são o Benefício de Prestação

\footnotetext{
1 Luana PINHEIRO et al., 2008.

${ }^{2}$ Henrietta MOORE, 1996.
} 
Continuada (BPC) e o PBF, sendo o primeiro sem e o segundo com condicionalidades. As transferências condicionadas de renda priorizam o repasse de renda às mulheres $e$ envolvem-nas em uma rede de obrigações com as ações estatais. Desse modo, referimonos a políticas e programas com claro marcador de gênero e, a partir de perspectivas feministas, os interpelamos acerca da condição de cidadania das mulheres usuárias.

Ao cruzarmos as demandas por cidadania com a problemática da pobreza e, de modo mais amplo, com a persistente situação de desigualdade brasileira, devemos tomar sexo e gênero, assim como cor e raça, como dimensões indispensáveis de análise acerca das políticas sociais. Gênero e raça devem, portanto, ser mobilizados como categorias de análise. Nesse sentido, o Retrato das desigualdades de gênero e raça traz relevante contribuição ao apresentar dados macrossociais desagregados por sexo e cor e raça que nos permitem captar as interconexões desses dois marcadores sociais na (re)produção das desigualdades. Os dados sobre renda explicitam, de modo mais cabal, o quadro de discriminação contra mulheres e negros e, ainda, a "dupla discriminação sofrida pelas mulheres negras". ${ }^{3}$

Esses dados são exemplos que demonstram parte da problemática relacionada à cidadania das mulheres, em especial das mulheres negras. Devemos, ainda, tomar em consideração que a divisão sexual do trabalho, as responsabilidades com as tarefas de reprodução, sobretudo quanto às atribuições domésticas, e a quase interdição dos espaços de poder às mulheres, notadamente as negras, são fatores que contribuem para obstar a conquista das mulheres no campo da cidadania. ${ }^{4}$

Conforme observação de Lena Lavinas e Marcelo Nicoll, ${ }^{5}$ ainda que as condições de pobreza não sejam determinadas pela questão de gênero, os dados nos revelam que esse é um marcador que influencia as situações das famílias pobres quando analisamos, por exemplo, o fenômeno da chefia familiar feminina entre famílias pobres, grupo no qual esse fenômeno é mais expressivo se comparado às famílias com maior renda. Nesse caso, articula-se uma vulnerabilidade adicional. ${ }^{6}$

No Brasil, 22,3\% das famílias eram chefiadas por mulheres em 1993. No ano de 2007 essa proporção aumentou para 33\%. ${ }^{7}$ Tratando-se de Londrina e comparando-se as famílias chefiadas por mulheres, sem o critério de renda, observa-se que, em 1991, as mulheres respondiam por $20,42 \%$ das famílias e, em 2000 , esse número saltou para $27,53 \%$, o que representa um crescimento de $34,81 \% .^{8}$

Se nos perguntarmos em qual estrato de renda a chefia familiar feminina está mais presente, perceberemos diferenciais significativos entre as famílias com rendimento familiar por pessoa de até $1 / 2$ salário mínimo e as famílias com renda superior a 2 salários mínimos. No primeiro estrato social, as famílias chefiadas por mulheres cresceram de $25,57 \%$ para $37,7 \%$, o que representa um aumento de $47,43 \%$. No segundo estrato social, as famílias

\footnotetext{
${ }^{3}$ PINHEIRO et al., 2008, p. 33.

${ }^{4}$ Maria Lygia Quartim de MORAES, 2003.

${ }^{5}$ Lena LAVINAS e Marcelo NICOLL, 2006.

${ }^{6}$ Adotamos a referência de Mary Garcia CASTRO (2002), que compreende a vulnerabilidade social como o resultado negativo da relação entre a disponibilidade dos recursos materiais ou simbólicos dos atores, sejam eles indivíduos ou grupos, e o acesso à estrutura de oportunidades sociais, econômicas, culturais que provêm do Estado, do mercado e da sociedade. Esse resultado se traduz em debilidades ou desvantagens para o desempenho e a mobilidade social dos atores. Esse enfoque faz referência a três elementos de conformação de situações de vulnerabilidade de indivíduos, famílias ou comunidades: recursos materiais ou simbólicos, também chamados de ativos (Carlos Henrique FILGUEIRA, 2001); estruturas de oportunidades dadas pelo mercado, pelo Estado e pela sociedade; e estratégias de uso dos ativos.

7 PINHEIRO et al., 2008.

${ }^{8}$ IBGE, 2000.
} 
chefiadas por mulheres cresceram de $17,54 \%$ para $25,54 \%$, o que representa um aumento de $45,61 \%$. O crescimento entre os dois estratos de renda é quase equivalente, com os números um pouco mais elevados entre as famílias pobres.

Comparando-se as famílias desses dois estratos de renda, percebe-se que a chefia familiar feminina concentra-se justamente entre os grupos sociais mais vulneráveis e ainda Ihes acrescenta um grau a mais de vulnerabilidade por serem, muitas vezes, famílias monoparentais. É coerente com esses dados a suposição de que no universo de famílias pobres chefiadas por mulheres exista uma ocorrência maior entre aquelas chefiadas por mulheres negras, pois existem mais famílias negras em situação de pobreza e miséria. A esse respeito serve de comparativo o dado segundo o qual $11,7 \%$ dos domicílios urbanos em favelas são chefiados por mulheres brancas, enquanto $26 \%$ deles são chefiados por mulheres negras. ${ }^{9}$ Esse fenômeno revela a importância da incorporação da perspectiva de gênero, bem como do quesito cor e raça, nos programas de enfrentamento à pobreza e de desenvolvimento social.

Ao ser incluída no PBF, a mulher é tomada como representante do grupo familiar, vale dizer, o grupo familiar é materializado simbolicamente pela presença da mulher. Esta, por sua vez, é percebida tão somente por meio de seus 'papéis femininos', que vinculam, sobretudo, o ser mulher ao ser mãe, com uma identidade centrada na figura de cuidadora, especialmente das crianças e dos adolescentes, dadas as preocupações do PBF com esses grupos de idade. O papel social de cuidadora pode até, em algumas situações, ser desempenhado por outra mulher, como, por exemplo, a avó ou tia da criança ou do adolescente. Contudo, seguirá sendo um 'papel feminino'. Logo, o cuidado preserva, no âmbito do PBF, seu caráter vinculado aos papéis de gênero. Assim, tanto a maternidade (relacionada à procriação e/ou ao papel social de mãe) quanto a maternagem (o cuidado da criança e do adolescente desempenhado por outra mulher, geralmente com vínculo de parentesco, porém sem se designar como sua mãe) são funções focalizadas pelo PBF.

De acordo com observações e entrevistas realizadas no estudo de caso, em uma família beneficiária do PBF a mulher-mãe ou aquela que eventualmente a substitui na função de maternagem tem como responsabilidade, entre outras: a) a realização do Cadastro Único para inclusão da família no programa; b) a atualização do referido cadastro sempre que ocorre alguma modificação na situação familiar (por exemplo, mudança de endereço, alteração no número de pessoas no domicílio, oscilação nos rendimentos); c) o recebimento do recurso repassado pelo programa; d) a aplicação do recurso de modo a beneficiar coletivamente o arranjo familiar; e) o controle sobre crianças e adolescentes, tendo em vista o cumprimento das condicionalidades do programa; e f) a participação em reuniões e demais atividades programadas pela equipe de profissionais responsáveis pela execução e pelo acompanhamento do programa.

Ao analisar o Programa Bolsa Escola, antecessor do PBF, Carin Klein ${ }^{10}$ observou que

\begin{abstract}
Ao pagar um valor determinado, definido como salário, pretende-se que a mãe sinta "[...] a dignidade de seu trabalho e a importância de investir na construção de um futuro melhor para os seus filhos". Como importantes argumentos apresentados na cartilha 100 perguntas e respostas que você precisa saber sobre o Bolsa-Escola, encontramos que é através do Programa que se investe também na "valorização da mulher" ao torná-la a "provedora do núcleo familiar", contribuindo, assim, para que ela assuma um papel ativo na vida da família e no "controle da educação" de seus/suas filhos/as. Buarque considera que o benefício da Bolsa-Escola, pago à mãe para que ela cuide
\end{abstract}

9 PINHEIRO et al., 2008.

${ }^{10}$ Carin KLEIN, 2005, p. 37. 
da educação de seu/sua filho/a, representa um "Emprego Social", pois garante estabilidade econômica e social para toda a família.

Carin Klein"1 chama atenção na atuação desses programas que atuam para converter em termos equivalentes categorias como "mulher" e "mãe". A estratégia de inclusão e de interpelação das mulheres supõe a seguinte operação ideológica: mulher = mãe ou família = mãe. Essa estratégia relaciona-se ao processo de revalorização da família. Diante dos novos desenhos das políticas sociais voltadas para o combate à pobreza e dirigidas às famílias, uma antiga questão feminista deve ser retomada: qual é o lugar das mulheres na família e na relação com o Estado? Nesse aspecto, as contribuições feministas atualizam o debate sobre os riscos da cristalização dos papéis sociais de gênero que aprisionam as mulheres nas tarefas relacionadas ao cuidado, à maternagem e, de modo mais geral, à reprodução social.

As atividades reprodutivas das mulheres pobres aparecem como recurso aditivo dos programas de combate à pobreza, de modo a tornar mais eficientes os impactos produzidos pela transferência condicionada de renda. As contrapartidas do PBF, relacionadas à saúde e à educação, ${ }^{12}$ exigidas notadamente das mulheres, facilitam a ação da política na tarefa de mobilizar as mulheres para o cumprimento das obrigações, as quais são primordialmente consideradas 'femininas'.

Ocorre no PBF uma estratégia semelhante à encontrada em ações estatais junto às organizações populares de mulheres, pelo menos desde a década de 1980. Nessas ações são fomentadas as demandas que focalizam as necessidades das mulheres, como é o caso dos tradicionais projetos de geração de renda com trabalhos manuais. ${ }^{13}$ Essas demandas correspondem às necessidades práticas, visando minimizar as dificuldades das mulheres dentro do padrão das relações de gênero, sem atacar diretamente a questão da subordinação feminina e sem alterar, portanto, o padrão das relações sociais de gênero. ${ }^{14}$ As necessidades das mulheres, nesses casos, são interpretadas em relação à situação de pobreza, sem levar em consideração a situação de subordinação feminina.

No caso de ações como o PBF, as preocupações quanto à pobreza são dirigidas à família. O próprio direito ao recurso transferido é tipificado em termos de benefício à família, e não a indivíduos. Como consequência, as demandas feministas por atenção prioritária à situação das mulheres vão se transformando em familismos, que, no processo de tradução político-cultural, substituíram a demanda por empoderamento das mulheres por demandas que visam ao fortalecimento das famílias. ${ }^{15} \mathrm{~A}$ defesa da família como foco de preocupação é uma característica constitutiva de políticas de combate à pobreza como o PBF. Na medida em que a defesa da família é operacionalizada com foco nas funções femininas, logo essas políticas familistas reforçam a associação da mulher à maternidade.

O que nos interessa destacar para os objetivos da análise aqui proposta é que, mesmo com revisões teóricas a respeito da subordinação feminina, a maternidade segue sendo um ponto de debate e de preocupação entre as feministas, especialmente nas circunstâncias atuais de políticas familistas.

\footnotetext{
11 KLEIN, 2005.

${ }^{12}$ De acordo com orientações do Ministério do Desenvolvimento Social e Combate à Fome (MS), "ao entrar no Programa, a família se compromete a cumprir as condicionalidades do Bolsa Família nas áreas de saúde e educação, que são: manter as crianças e adolescentes em idade escolar freqüentando a escola; e cumprir os cuidados básicos em saúde, que é seguir o calendário de vacinação para as crianças entre 0 e 6 anos, e a agenda pré e pós-natal para as gestantes e mães em amamentação" (2009, grifo nosso).

${ }^{13}$ Silvana Aparecida MARIANO, 2001 e 2008.

${ }^{14}$ Leda Maria Vieira MACHADO, 1999.

${ }^{15}$ Sonia ALVAREZ, 2000.
} 
A família é, entre outros aspectos, o lugar social e simbólico ${ }^{16} \mathrm{em}$ que a diferença, especialmente a diferença sexual, é assumida como base e, ao mesmo tempo, construída como tal. Chiara Saraceno comenta que não se trata apenas da necessidade fisiológica da reprodução e muito menos de legitimar a sexualidade, na família o reconhecimento de que a humanidade tem dois sexos torna-se princípio organizativo social global e a estrutura que organiza as relações sociais e os destinos individuais. A autora comenta que

\begin{abstract}
Lugar em que os dois sexos se encontram e convivem, a família é também o espaço histórico e simbólico no qual e a partir do qual se desenvolve a divisão do trabalho, dos espaços, das competências, dos valores, dos destinos pessoais de homens e mulheres, ainda que isso assuma formas diversas nas várias sociedades. É, antes de mais nada, em nível da família que o fato de se pertencer a um determinado sexo se transforma em destino pessoal, implícita ou explicitamente regulamentado e que se situa numa hierarquia de valores, poder, responsabilidade.
\end{abstract}

A gerência do recurso para beneficiar a família, principalmente as crianças, tem sido citada por diferentes autores e gestores dos programas de combate à pobreza, nos diferentes escalões, desde o âmbito federal até o municipal, e é nesse sentido que tem recaído sobre a mulher a preferência pela titularidade do benefício. As mulheres, na sua grande maioria, realmente utilizam o benefício para melhoria das condições de vida da família, em particular das crianças, nos quesitos alimentação, vestuário, compra de material escolar, mobiliário para a casa e material de construção para melhoria das condições físicas da casa.

A família moderna, como família dos sentimentos e da educação, ${ }^{18}$ nasce em torno das figuras da mãe e da criança, não só porque o espaço que as circunscreve é, cada vez mais, exclusivamente o doméstico-familiar, mas "porque se trata exatamente de duas figuras interdependentes. É a mulher identificada como mãe, não só no sentido biológico, mas também em termos afetivos e educativos, que exprime antes de tudo esta nova atenção e responsabilidade familiar para com as crianças".

Chiara Saraceno ${ }^{19}$ observa que o programa educativo e moral que está no centro da família moderna diz respeito à mãe como educadora e como sujeito a educar na própria "autêntica e natural vocação".

Quanto à utilização dos recursos para uso em benefício exclusivo dos filhos, a autora afirma, tendo por base a realidade europeia, que neste caso não difere da brasileira, que mais frequentemente a mulher-mãe renuncia "naturalmente a consumos individuais a favor dos consumos dos outros membros da família, o marido ou os filhos". E é sempre ela que põe todo o dinheiro no caixa comum, no caso de trabalhar, enquanto o marido e, eventualmente, os filhos descontam uma parte para si. ${ }^{20} \mathrm{~A}$ autora afirma, com base em uma pesquisa inglesa feita por Pahl, o quanto pode ser difícil, para uma mulher, distinguir entre despesas familiares e despesas para si, mesmo quando o dinheiro gasto é ganho por ela. $\mathrm{O}$ uso de recursos por parte da mulher constitui-se em um bom indicador, embora não único, das dinâmicas de poder e controle dentro da família.

Os discursos sobre feminilidade e maternidade apropriados pelo PBF com o intuito de potencializar o desempenho de suas ações no combate à pobreza reforçam o lugar

\footnotetext{
${ }^{6}$ Chiara SARACENO, 1997.

17 SARACENO, 1997, p. 14.

18 SARACENO, 1997, p. 194.

19 SARACENO, 1997.

${ }^{20}$ SARACENO, 1997, p. 195.
} 
social tradicionalmente destinado às mulheres: a casa, a família, o cuidado, o privado, a reprodução. É preciso que o programa se questione sobre o peso de cada uma dessas categorias para a subordinação e a autonomia das mulheres.

\section{Considerações finais}

A pesquisa qualitativa do estudo de caso em Londrina e as reflexões suscitadas nos possibilitaram apreender como uma política de combate à pobreza pode atuar para reforçar lugares sociais marcados pelos papéis tradicionais de gênero e, ao fazê-lo, encontra sérias dificuldades para se viabilizar como um programa de redução das desigualdades. A experiência coloca em evidência obstáculos que são gerados pelo uso acrítico de tradições sociais e culturais, que, na realidade, atuam de modo a favorecer a (re)produção das desigualdades. Os papéis de gênero, ao mesmo tempo binários e complementares, simbolizam essas tradições incorporadas pelo PBF. Consideramos que o PBF teria mais contribuições a oferecer na luta pela redução das desigualdades se viesse a incorporar concepções mais críticas acerca dos papéis de gênero.

Perante a política de assistência social, a família é identificada pela figura da mulher, e não pela do homem. E a mulher, por sua vez, é considerada com base nas funções maternas, o que fixa e essencializa o sujeito mulher, vinculando-o à maternidade. Consideramos, à luz de influências feministas a partir de autoras como, por exemplo, Joan Scott, ${ }^{21}$ Judith Butler, ${ }^{22}$ Chantal Mouffe ${ }^{23}$ e Nancy Fraser, ${ }^{24}$ que os processos de fixação e 'essencialização' de identidades, de homens e mulheres, constituem-se em sérios obstáculos para uma sociedade democrática, a qual exige a construção de sujeitos plurais e identidades contingentes. Consideramos, ainda, que a fixação de papéis sexuais, a exemplo do aprisionamento das mulheres às tarefas reprodutivas, contribui para o reforço da lógica binária de classificação e para a (re)produção da subordinação feminina. ${ }^{25}$

O modo como o Programa Bolsa Família atua em Londrina cria mecanismos que minimizam a responsabilidade dos homens e produzem a responsabilização das mulheres com o cuidado de crianças e adolescentes. Ao fazê-lo, contribui para a cristalização dos papéis de gênero.

\section{Referências bibliográficas}

ALVAREZ, Sonia. "Em que Estado está o feminismo latino-americano? Uma leitura crítica das políticas públicas com 'perspectiva de gênero'”. In: FARIA, Nalu; SILVEIRA, Maria Lúcia; NOBRE, Miriam (Orgs.). Gênero nas políticas públicas: impasses, desafios e perspectivas para a ação feminista. São Paulo: SOF, 2000. p. 9-25. (Coleção Cadernos Sempreviva).

BUTLER, Judith. "Fundamentos contingentes: o feminismo e a questão do 'pós-modernismo'”. Cadernos Pagu, Campinas, n. 11, p. 11-42, 1998.

. Problemas de gênero: feminismo e subversão da identidade. Rio de Janeiro: Civilização Brasileira, 2003.

CASTRO, Mary Garcia. "Jovens em situação de pobreza, vulnerabilidades sociais e violência". Cadernos de Pesquisa, São Paulo: Fundação Carlos Chagas, n. 116, p. 143-176, jul. 2002.

\footnotetext{
${ }^{21}$ Joan SCOTT, 2002.

22 Judith BUTLER, 1998 e 2003.

${ }^{23}$ Chantal MOUFFE, 1999 e 2003.

24 Nancy FRASER, 2002.

${ }^{25}$ MARIANO, 2005 e 2008.
} 
FILGUEIRA, Carlos Henrique. "Estructura de oportunidades y vulnerabilidad social: aproximaciones conceptuales recientes". In: SEMINARIO VULNERABILIDAD, 2001, Santiago de Chile: CEPAL.

FRASER, Nancy. "Políticas feministas na era do reconhecimento: uma abordagem bidimensional da justiça de gênero". In: BRUSCHINI, Cristina; UNBEHAUM, Sandra Gouretti. (Orgs.). Gênero, democracia e sociedade brasileira. São Paulo: FCC; Ed. 34, 2002. p. 59-78.

KLEIN, Carin. "A produção da maternidade no Programa Bolsa-Escola". Revista Estudos Feministas, Florianópolis, v. 13, n. 1, p. 31-52, jan./abr. 2005.

LAVINAS, Lena; NICOLL, Marcelo. "Pobreza, transferências de renda e desigualdades de gênero: conexões diversas”. Revista Parcerias Estratégicas, Brasília, n. 22, p. 39-75, jun. 2006. Disponível em: http://www.cgee.org.br/parcerias/p22.php. Acessado em jul/2006. Acesso em: 9 nov. 2009.

MACHADO, Leda Maria Vieira. A incorporação de gênero nas políticas públicas: perspectivas e desafios. São Paulo: Annablume, 1999. MARIANO, Silvana Aparecida. Movimento de mulheres e Estado: ambigüidades da incorporação de gênero nas políticas públicas em Londrina. 2001. Dissertação (Mestrado em Sociologia Política) - Universidade Federal de Santa Catarina, Florianópolis, 2001.

. "O sujeito do feminismo e o pós-estruturalismo". Revista Estudos Feministas, Florianópolis: CFH/CCE/UFSC, v. 13, n. 3, p. 483-505, set./dez. 2005.

. "Modernidade e crítica da modernidade: a Sociologia e alguns desafios feministas às categorias de análise". Cadernos Pagu, Universidade Estadual de Campinas: IFCH, n. 30, p. 345-372, jun. 2008.

MINISTÉRIO DO DESENVOLVIMENTO SOCIAL E COMBATE À FOME. Perfil das famílias beneficiárias do Programa Bolsa Família. Brasília, DF, mar. 2007. 77 p. Disponível em: http:// www.mds.gov.br/bolsafamilia/o_programa_bolsa_familia/beneficios-e-contrapartidas. Acesso em: 9 set. 2009.

MOORE, Henrietta. Antropología y feminismo. 2. ed. Madrid: Ediciones Cátedra; Universitat de Valencia; Instituto de la Mujer, 1996.

MORAES, Maria Lygia Quartim de. "Cidadania no feminino". In: PINSKY, Jaime; PINSKY, Carla Bassanezi (Orgs). História da cidadania. São Paulo: Contexto, 2003. p. 495-515.

MOUFFE, Chantal. "Feminismo, cidadania e política democrática radical". In: _. . Debate Feminista. São Paulo: Cia. Melhoramentos, 1999. p. 29-47. Edição Especial. (Cidadania e Feminismo).

. La paradoja democrática. Barcelona: Gedisa Editorial, 2003.

PINHEIRO, Luana et al. Retrato das desigualdades de gênero e raça. 3. ed. Brasília: Ipea; SPM: UNIFEM, 2008. 36 p.

SARACENO, Chiara. Sociologia da família. Lisboa: Editorial Estampa Ltda., 1997.

SCOTT, Joan. A cidadã paradoxal: as feministas francesas e os direitos do homem. Florianópolis: Editora Mulheres, 2002.

\footnotetext{
Gender and Poverty Fight: the Family Donation Program

Abstract: The Brazilian social assistance policy is guided by the perspective of poverty fight efforts, which prioritize the conditioned income transfer. These programs privilege the income transfer to women and involve them in a net of obligations and conditions, as it is done in the Family Donation Program. The practice within Family Donation Program highlights some contradictions between the State actions and the feminist demands, especially those concerning the motherhood problem. This is thus a core question for the dialogue between the feminism and the social policies sponsored by the State.
}

Key Words: Family Donation Program; Poverty Fight; Motherhood; Gender; Feminism. 